\title{
Prenatal effects of ethanol on the behavioral development of the rat
}

\author{
MARIE DEMERS and GILLES KIROUAC \\ Ecole de Psychologie, Universite Laval, Quebec, GIK 7P4, Canada
}

\begin{abstract}
Pregnant female rats received daily intravenous ethanol infusions from Day 5 to Day 18 of pregnancy. Other females received saline infusions or no treatments. At birth, the offspring were fostered to nontreated mothers, and their behavioral development was studied until they were 21 days old. Fourteen tests of neuromotor development were administered to the subjects in the three groups in order to compare their speed of behavioral maturation. The results indicated that the animals born to mothers that received ethanol during pregnancy tended to have a slow behavioral development: in 8 out of 14 tests, they reached the performance criterion significantly later.
\end{abstract}

Many studies have shown that the behavior of animals was affected by drugs that had been administered during pregnancy (Coyle, Wayner, \& Singer, 1976). However, there are very few data dealing with the prenatal behavioral effects of ethanol. In humans, maternal alcoholism seems to induce deleterious effects in young infants: malformations, growth retardation, and mental deficiency (Jones \& Smith, 1975). Some recent data in rats indicated that ethanol, when administered during pregnancy, induced some biochemical changes that could be behaviorally relevant. For instance, some changes in protein synthesis in the brain were reported (Rawat, 1975). Offspring of female rats receiving alcohol during pregnancy and lactation showed a decrease in catecholamines storage (Lau, Thadani, Schanberg, \& Slotkin, 1976) and in brain acetylcholine as well as an increase in GABA and glutamate (Rawat, 1977).

At the behavioral level, it was found that prenatal ethanol administration induced a quicker acquisition rate of shuttlebox avoidance (Auroux \& Dehaupas, 1970). However, Phillips and Stainbrook (1976) found a lower ability in rats to form learning sets. Those contradictory results could be due to a difference in the learning tasks that were used in the two studies. It may also be a consequence of a difference in the period during which ethanol was offered to the experimental subjects. Also, Bond and Di Giusto (1977) observed an increased activity level in an open field. The purpose of the present study was to investigate the effects of alcohol administration during pregnancy on the development of a series of behavioral responses in infant rats.

\section{METHOD}

\section{Subjects}

Twelve Sprague-Dawley nulliparous female rats from ARS Sprague-Dawley (Madison, Wisconsin) were used. The animals were
3 months old. They were kept in individual cages in a room where temperature and humidity were controlled and where there was a 12-h-light-dark cycle.

\section{Procedure}

All females, except those in the control group, were implanted with an intravenous cannula (Weeks, Note 1.). After a recovery period of at least 2 weeks, the females were paired with a male. Daily vaginal smears were taken in order to ascertain pregnancy. Six pregnant females received intravenous infusions of ethanol from Gestation Day 5 to Gestation Day 18 (for a total of 14 days) with infusion pumps (Sage, Model 355). Every daily infusion lasted $2 \mathrm{~h}$, and the mean amount of infused alcohol solution was $5 \mathrm{cc}$. For the first 3 infusion days, the dosage was $1.2 \mathrm{~g} / \mathrm{kg}$ of ethanol in a $10 \% \mathrm{v} / \mathrm{v}$ solution. Thereafter, the animals received $1.5 \mathrm{~g} / \mathrm{kg}$ of ethanol in a $12.5 \%$ solution $\mathrm{v} / \mathrm{v}$. Three other females received a daily physiological saline infusion of $5 \mathrm{cc}$. The last three females received no treatment.

After birth, every litter from all females in the three groups was reduced to eight subjects (four males and four females) and fostered to another female that had received no treatment during its pregnancy. The offspring were tested daily from the day of birth to Day 21 .

The surviving infant rats were distributed between groups as follows: 24 subjects from three litters were in the group where the mothers received no treatment during pregnancy (Group C); 8 subjects from two litters were in the group where the females received saline infusions from Day 5 to Day 18 of pregnancy (Group S); 10 subjects from two litters were in the group where the mothers received ethanol infusions from Day 5 to Day 18 of pregnancy (Group A).

\section{Behavioral tests}

The tests were based on the procedures described by Altman and Sudarshan (1975). A daily open-field test was run from Day 1 of birth: each individual animal from each litter, was put for $1 \mathrm{~min}$ in an open field $(46 \times 24 \mathrm{~cm})$ and observed for the occurrence of certain responses. Briefly, these responses can be described as follows, indicating the final performance expected from the subjects. The results are expressed as the day when that performance was first encountered.

Elevation of the head. In the first $\mathbf{2}$ days after birth, young rats keep their heads above the supporting surface most of the time. Thereafter, that behavior decreases to a very low level. Around Day 10, the behavior tends to increase again. The experimenter took note of the first day that response occurred again during at least half the observation period of $1 \mathrm{~min}$. 
Elevation of the forelimbs and shoulders. By the end of the 1st week after birth, the animal tends to elevate its shoulders from the ground. The experimenter took note of the first day the animal elevated its shoulders for at least half the observation period of $1 \mathrm{~min}$

Elevation of the hindlimbs and pelvis. During the second half of the 2nd week, the hindlimbs of the young rat become sufficiently mature to support the weight of the pelvis. The experimenter took note of the first day the animal supported its pelvis with its hindlimbs for at least half the observation period of $1 \mathrm{~min}$.

Pivoting. In the 1st days after birth, the animal emits spontaneous movements of the forelimbs which produce a circular motion or pivoting of the animal, since the hindlimbs do not yet support movements of the forelimbs. The experimenter noted the 1st day when the animal could induce a turning motion of more than $180^{\circ}$.

Crawling. Around the beginning of the 2nd week, the subject succeeds in moving forward without elevating its trunk. The traction is provided by hindlimb movements. The experimenter noted the 1st day that this response was observed.

Walking. Around Day 12, forelimbs and hindlimbs are supporting the body when the animal moves. The experimenter took note of the 1st day when that behavior was observed during the $1 \mathrm{~min}$ observation period.

Head pointing. The animal, when in the open field, points its head upward at an angle of more than $45^{\circ}$. The experimenter noted the first day when this behavior was observed at least once during the 1-min observation period.

Rearing without support. Note was taken of the 1st day the subject reared on its hindlegs at least once during the 1-min observation period without any support from its forelimbs.

Righting on a surface. Starting on Day 1 , the rat was lifted from the supporting surface and placed on its back. The experimenter noted the first day when the rat took less than $5 \mathrm{sec}$ to completely right itself.

Righting in mid-air. Starting on Day 9, the rat was dropped upside down from a height of $30 \mathrm{~cm}$ above a padded surface. Three trials were done each day until the animal succeeded in completely righting itself before landing in all three trials.

Cliff avoidance. Starting on Day 1, the animal was placed on the edge of a wooden platform with its nose and forefeet over the edge. This test was repeated daily until the rat backed up or turned sideways in less than $5 \mathrm{sec}$.

Negative geotaxis. On Day 12, the rat was placed on an incline $\left(25^{\circ}\right)$, head pointing downward. The animal had to rotate its body axis $180^{\circ}$ and climb upward within $30 \mathrm{sec}$. If, before rotating and climbing, the animal stepped down, it was given another trial. The procedure was repeated if necessary, provided that no more than five trials were given to the animal within the 30 -sec daily test period. The experimenter took note of the first day the animal emitted the criterion response.

Ascending a wire-mesh surface. A $13 \mathrm{~mm}$ wire-mesh surface of $31 \mathrm{~cm}$ length was placed at an angle of $75^{\circ}$ into cold water. In Day 10, the rat was placed on the wire mesh so that its hindlimbs and tail touch the cold water. The test was repeated daily until the animal climbed up to the top of the surface within $30 \mathrm{sec}$.

\section{Body Weight}

Finally, the body weight of all animals was taken on Day 1 . The body weight of the animals kept for testing was also taken on Days 2, 3, 4, 8, 12, 16, and 21.

\section{RESULTS}

Among the three rats that received saline infusions during gestation, one gave birth to 7 living offspring out of 8; the second gave birth to 3 living offspring out of 6 , and of those 3,2 died at the age of 2 days; the last female died on Gestation Day 23 before giving birth to any offspring. Among the six females that received ethanol infusions during gestation, three gave birth to litters; one female gave birth to 5 offspring, all of which were dead; the second one gave birth to 4 living offspring out of 11 , finally, a third female gave birth to 6 living offspring out of 7. A fourth female had to be discarded because its cannula was not functioning well; a fifth one died on Gestation Day 19; and the sixth female aborted on Day 11 of gestation. Postmortem examinations of the two females that died during gestation revealed that there were at least 12 fetuses in the uterus of each female.

The number of animals that were found dead at birth was higher in Group A (13/23) than in Group S (4/14). No rat was found dead at birth in Group C.

During the postnatal development period, the mean body weight of the rats in Group $C$ increased from $7 \mathrm{~g}$ on Day 1 to $40 \mathrm{~g}$ on Day 21. Animals in Group A show approximately a same pattern of body weight increase (Figure 1) even if their mean body weight at birth was significantly lower than that of Group $\mathrm{C}[\mathrm{H}(2)=8.51, \mathrm{p}<.05]$. This means that the animals in Group A could generally reach the same level of body growth by normal weaning time.

Table 1 gives, for the three groups of subjects, the mean days at which the performance criteria were reached for all the tests that were performed. Parametric or nonparametric analyses of variance were performed on those data and yielded a significant overall difference for 8 of the 14. When appropriate,

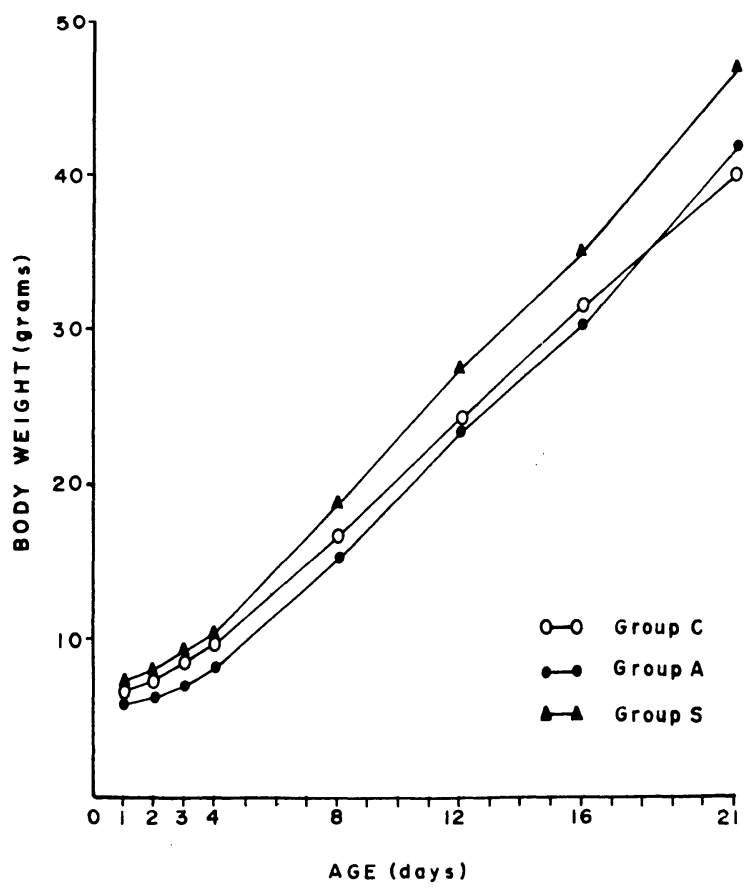

Figure 1. Evolution of body weight as a function of age. 
multiple-comparison Duncan tests showed that Group A subjects reached the performance criterion at a significantly later mean day for the following tests $(p<.01)$ : elevation of the head, elevation of the forelimbs and shoulders, elevation of the hindlimbs and pelvis. For tests where a nonparametric analysis of variance yielded a significant effect, multiple comparisons were done with the Mann-Whitney test. Those analyses showed that Group A was significantly retarded for the following behavioral tests: negative geotaxis $(p<.05)$, ascending a wire-mesh surface $(\mathrm{p}<.05)$, and walking $(\mathrm{p}<.01)$. Group A subjects had a significantly retarded performance in the righting in mid-air test but only in comparison with Group S $(p<.01)$ : it was not significantly different from Group C. Finally analyses of variance revealed no significant differences for the following tests: pivoting, crawling, head pointing, cliff avoidance, righting on a surface and rearing without support.

\section{DISCUSSION}

The purpose of this experiment was to investigate the effects of the infusion of ethanol to pregnant female rats on the behavioral development of their offspring. Ethanol rapidly crosses the placental barrier to be found in the fetal blood (Mann, Bhakthavathsalan, Liu, \& Makowski, 1975). It was found that a particularly high concentration of ethanol could be observed in the cerebellum of macaques and hamsters (Idänpään-Heikkilä, Fritchie, Ho, \& McIsaac, 1971). Although no data exist on the rat, it is plausible to assume that alcohol is also found in the cerebellum of fetal rats. Our data showed that maternal ethanol infusion during pregnancy affected the development of some locomotor performance in the offspring. This finding is in agreement with the observation that ethanol was present in high concentrations in the cerebellum of the fetuses when administered to pregnant females.
Our data indicated that the infusion of ethanol during pregnancy induced a reduction in the rate of behavioral development of the offspring. Those findings support the idea that a prenatal treatment of that kind slows down the maturation of the central nervous system. This is in agreement with Thadani, Lau, Slotkin, and Schanberg (1977) and Thadani, Slotkin, and Schanberg (1977). They found that following prenatal ethanol administration there was an alteration in the developmental pattern of ornithine decarboxylase (ODC) activity in the brain. This change was interpreted by the authors as an indication of a disturbance in the growth and development of the brain.

Moreover, Rawat (1975) found that maternal alcohol consumption induced some important biochemical changes in the fetal and neonatal brains. The cerebral content of RNA and DNA was significantly lower in the brains of the offspring. These changes were seen by Rawat as possibly responsible for the depletion in the brain cells of essential protein molecules affecting the metabolic functioning of the brain.

At birth, the offspring in the alcohol group had a lower body weight. Some similar data were obtained in other studies (Auroux \& Dehaupas, 1970; Pilstrom \& Kiessling, 1967; Tze \& Lee, 1975). That difference cannot be due to the fact that the subjects in that group came from bigger litters, since there were fewer subjects per litter in the alcohol group. The evolution of body weight in the alcohol group subjects was similar to that of the other groups, and the difference between the groups disappeared long before weaning time. Accordingly, it does not seem plausible to pretend that the differences in behavioral development between the groups are due to differences in the rate of body weight increases.

A similar evolution of body weight was observed in rats born to females which had received ethanol during pregnancy and fostered to nontreated females (Pilström \& Kiessling, 1967). However, when the

Table 1

Mean Age of Occurrence of the Criterion Performance (Days) for the Various Behavioral Tests

\begin{tabular}{|c|c|c|c|c|}
\hline Tests & $\begin{array}{c}\text { Group C } \\
\text { (24 Subjects) }\end{array}$ & $\begin{array}{c}\text { Group S } \\
\text { (8 Subjects) }\end{array}$ & $\begin{array}{c}\text { Group A } \\
\text { (10 Subjects) }\end{array}$ & \\
\hline Elevation of the head & 12.5 & 12.25 & 14.3 & $\mathrm{~F}=22.15 * *$ \\
\hline Elevation of forelimbs and shoulders & 12.04 & 12.25 & 14.5 & $\mathrm{~F}=37.69 * *$ \\
\hline Elevation of hindlimbs and pelvis & 13.25 & 12.38 & 14.9 & $\mathrm{~F}=12.87 * *$ \\
\hline Righting in mid-air & 18.46 & 16.88 & 18.9 & $\mathrm{~F}=5.11^{*}$ \\
\hline Crawling & 7.38 & 7.5 & 8.5 & $F=2.64$ \\
\hline Head pointing & 7.42 & 7.63 & 8.8 & $F=1.05$ \\
\hline Cliff avoidance & 14.08 & 13.38 & 13.6 & $F=1.49$ \\
\hline Rearing without support & 17.00 & 16.5 & 17.5 & $\mathrm{H}=.87$ \\
\hline Ascending a wire-mesh surface & 15.95 & 13.88 & 17.6 & $\mathrm{H}=7.27^{*}$ \\
\hline Walking & 13.17 & 12.0 & 15.14 & $\mathrm{H}=17.80 * *$ \\
\hline Negative geotaxis & 17.65 & 15.13 & 19.2 & $\mathrm{H}=17.45^{* *}$ \\
\hline Pivoting & 6.17 & 5.25 & 7.2 & $H=5.16$ \\
\hline Righting on a surface & 5.83 & 4.75 & 6.0 & $\mathrm{H}=2.47$ \\
\hline
\end{tabular}

${ }^{*} p<.05$

$* * \mathrm{p}<.01$ 
subjects were reared by their biological mothers, the increase in body weight was significantly retarded (Auroux \& Dehaupas, 1970; Pilström \& Kiessling, 1967). So the fostering procedure, which was similar to the one used in our own experiment, could eliminate postnatal confounding variables. Similarly, due to the fostering procedure, out data on the retardation of behavioral development cannot be interpreted as a result of a disturbance in maternal behavior in lactation that would have been induced by the infusion of ethanol during pregnancy.

In the present investigation, ethanol was administered from Day 5 to Day 18 of pregnancy and the dosage was not varied between different experimental groups. According to Altman and Dittmer (1962), the 2nd week of pregnancy is the most important period for the anatomical development of the central nervous system. It would be interesting to know what the effects would be of varying between groups the period of ethanol administration during pregnancy: before, during, and after the "critical" period of nervous system development. Moreover, it is plausible to believe that different dosages might have different effects, depending on the period of ethanol administration. There is a need for further work on that problem. It is also possible that different behaviors would be affected if the dosages and periods of treatment were varied. Our data indicated that not all behavioral development measures were affected by the prenatal ethanol treatment.

Finally, our results are in agreement with human data on the fetal alcohol syndrome. Among the characteristics of that syndrome, it was generally reported that it induced growth retardation in young infants born to alcoholic mothers (Jones \& Smith, 1975).

\section{REFERENCE NOTE}

1. Weeks, J. R. Cardiovascular techniques using unanesthetized and freely moving rats. Manuscript in preparation.

\section{REFERENCES}

Altman, J., \& Sudarshan, K. Postnatal development of locomotion in the laboratory rat. Animal Behaviour, 1975, 23, 896-920.
Altman, P. L., \& Dittmer, D. S. (Eds.). Growth. Washington, D.C: Federation of American Societies for Experimental Biology, 1962.

Auroux, M., \& Dehaupas, M. Influence de la nutrition de la mère sur le développement tardif du système nerveux central de la progéniture. Comptes rendu de la Société Biologique (Paris), 1970, 164, 1176-1182.

Bond, N. W., \& Di Giusto, E. L. Prenatal alcohol consumption and open-field behaviour in rats: Effects of age at time of testing. Psychopharmacology, 1977, 52, 311-312.

Coyle, J., WAYner, M. J., \& Singer, G. Behavioral teratogenesis: A critical evaluation. Pharmacology, Biochemistry and Behaviour, 1976, 4, 191-200.

IDÄNPäÄn-Heikkilä, J. E., Fritchie, G. E., Ho, B. T., \& McIsaAC, W. M. Placental transfert of C14-ethanol. American Journal of Obstetrics and Gynecology, 1971, 110, 426-428.

Jones, K. L., \& SMith, D. W. The fetal alcohol syndrome. Teratology, 1975, 12, 1-10.

Lau, C., Thadani, P. V.. Schanberg, S. M., \& Slotkin, T. A. Effects of maternal ethanol ingestion on development of adrenal catecholamines and dopamine-B-hydroxylase in the offspring. Neuropharmacology, 1976, 15, 505-507.

Mann, L. I., Bhakthavathsalan, A., Liu, M., \& Makowski, P. Placental transport of alcohol and its effect on maternal and fetal acid-base balance. American Journal of Obstetrics and Gynecology, 1975, 122, 837-844.

Pilstrom, L., \& Kiessling, K. H. Effect of ethanol on the growth and on the liver and brain mitochondrial functions of the offspring of rats. Acta Pharmacologia et Toxicologica, $1967,25,225-232$.

Phillips, D. S., \& Stainbrook, G. L. Effects of early alcohol exposure upon adult learning ability and taste preferences. Physiological Psychology, 1976, 4, 473-475.

Rawat, A. K. Ribosomal protein synthesis in the fetal and neonatal rat brain as influenced by maternal ethanol consumption. Research Communications in Chemical Pathology and Pharmacology, 1975, 12, 723-732.

RAwAT, A. K. Developmental changes in the brain levels of neurotransmitters as influenced by maternal ethanol consumption in the rat. Journal of Neurochemistry, 1977, 28, 1175-1182.

Thadani, P. V., Lau, C., Slotkin, T. A., \& Schanberg, S. M. Effect of maternal ethanol ingestion on neonatal rat brain and heart ornithine decarboxylase. Biochemical Pharmacology, 1977, 26, 523-527.

Thadani, P. V., Slotkin, T. A., \& Schanberg, S. M. Effects of late prenatal or early postnatal ethanol exposure on ornithine decarboxylase activity in brain and heart of developing rats. Neuropharmacology, 1977, 16, 289-293.

Tze, W. J., \& LeE, M. Adverse effects of maternal alcohol consumption on pregnancy and foetal growth in rats. Nature, $1975,257,479-480$.

(Received for publication February 22, 1978; revision accepted May 23, 1978.) 